\title{
ARTEFATOS DE CONTABILIDADE GERENCIAL: UM ESTUDO EM CURSOS DE GRADUAÇÃO DE CIÊNCIAS CONTÁBEIS DA REGIÃO SUDESTE DO BRASIL
}

\section{MANAGEMENT ACCOUNTING ARTIFACTS: A STUDY OF UNDERGRADUATE ACCOUNTING DEGREES SOUTHEASTERN BRAZIL}

0 artigo foi aprovado e apresentado : X Congresso de Administração, Sociedade e Inovação (CASI), realizado de 30/11 a 01/12 de 2017, em Petrópolis (RJ)

\section{RESUMO}

O ensino dos artefatos da Contabilidade Gerencial (ACG) compreende diversos campos do ensino contábil, assumindo, assim, um caráter multidisciplinar. Através da análise dos conteúdos referentes à Contabilidade Gerencial, adquire-se um entendimento sobre o ensino dos instrumentos gerenciais, bem como as relações entre o ensino acadêmico e as práticas gerenciais no cotidiano das organizações, o que reflete a sua grande relevância. O interesse pelo tema da pesquisa advém das sugestões de estudos futuros nos trabalhos escritos por Marques et al. (2016), Macedo et al. (2014), Souza, Borgert e Richartz (2012), Nascimento, Oliveira e Peter (2012), nos quais os autores ressaltavam a importância de serem realizados estudos acerca desta temática com amostra ampliada e maior quantidade de artefatos. Nessa perspectiva, este estudo, de cunho descritivo, tem por objetivo identificar quais artefatos de Contabilidade Gerencial são ministrados aos discentes do curso de Ciências Contábeis em instituições de ensino superior (IES) localizadas na Região Sudeste do Brasil, bem como, em quais estágios evolutivos os mesmos são classificados e em quais disciplinas normalmente são alocados. Assim, analisou-se as ementas dos referidos cursos disponibilizados pelas 53 IES que formam a amostra, totalizando 331 ocorrências de artefatos. Verificou-se que: há predominância do ensino de ACG tradicionais, sendo o custeio variável o mais frequente; a disciplina contabilidade de custos é a que congrega maior quantidade de artefatos em suas ementas; e, quando comparado aos outros estados da Região Sudeste, o estado de São Paulo possui a maior ocorrência de instrumentos gerenciais em suas ementas.

Palavras-chave: contabilidade gerencial; educação contábil; artefatos; ensino contábil

\begin{abstract}
The teaching of management accounting artifacts comprises several fields of accounting education, thus assuming a multidisciplinary character. Through the analysis of the contents related to management accounting, an understanding of the teaching of management instruments is acquired, as well as the relationships between academic teaching and management practices in routine of organizations, which reflects their great relevance. The interest in the research theme comes from the suggestions of future studies in the works written by Marques et al. (2016), Macedo et al. (2014), Souza, Borgert and Richartz (2012), Nascimento, Oliveira and Peter (2012), in which the authors emphasized the importance of studies on this subject with an expanded sample and a more artifacts. In this perspective, the purpose of this descriptive study is to identify which management accounting artifacts are taught to students of undergraduate accounting courses in education institutions located in the southeastern region of Brazil, as well as in which evolutionary stages they are classified and in which disciplines are normally allocated. Thus, the disciplines syllabus of the 53 education institutions that form the sample were analyzed, totalizing 331 occurrences of management accounting artifacts. The findings show predominance of traditional artifacts teaching with variable costing being the most frequent; the discipline cost accounting is the one that congregates more quantity of artifacts in the syllabuses analyzed; and the state of São Paulo has a greater occurrence of management instruments in the syllabuses when compared to the other Southeastern states.
\end{abstract}

Keywords: management accounting; accounting education; artifacts; accounting education
Thiago Cunha de Oliveira Mestrando em Ciências Contábeis pela Universidade Federal do Rio de Janeiro (UFRJ). Graduado em Ciências Contábeis pela Faculdade Presbiteriana Mackenzie Rio

Contato: Avenida Pasteur, 250 - sala 250 E-mail: thiaguhc@gmail.co

\section{Matheus de Lima Marques \\ Mestrando em Ciências Contábeis pela Universidade Federal do Rio de Janeiro (UFRJ). Graduado em Ciências Contábeis pela Universidade Federal do Rio de Janeiro (UFRJ). Atua como contador de algumas startups de 2018 té 0 momento atual. \\ Contato: Avenida Pasteur, 250 - sala 250 E-mail:mrmattmarques@gmail.com.}

Yara Consuelo Cintra

Doutora em Controladoria e Contabilidade pela FEA/USP, graduada em Administração e Ciências Contábeis. Atua como Professora do Departamento de Contabilidade da Faculdade de Administração e Ciências Contábeis da Universidade Federal do Rio de Janeiro (FACC/UFRJ) e no Programa de Pós-Graduação em Ciências Contábeis (PPGCC). Contato: Avenida Pasteur, 250 sala 250. Email: yaracintra@facc.ufr.br. 


\section{INTRODUÇÃO}

A Contabilidade Gerencial visa identificar, mensurar, acumular, preparar, interpretar e comunicar informações de uma entidade, assim funcionando como ferramenta de auxílio para a tomada de decisão dos gestores (HORNGREN; SUNDEN; STRATTON, 2004).

A fim de que tais processos efetivamente auxiliem os gestores, utilizam-se os chamados artefatos de Contabilidade Gerencial (ACG). Tais artefatos são caracterizados como filosofias de gestão e instrumentos que funcionam para interligar o campo teórico à prática empresarial, atuando como ferramentas utilizadas pelas entidades (BORINELLI, 2006).

Embora esses artefatos sejam amplamente utilizados no meio empresarial, eles já sofreram questionamentos acerca de sua adequação. Johnson e Kaplan (1987) afirmavam, dentre outras coisas, que havia uma lacuna entre o que era defendido e ensinado pela academia e os artefatos que eram, de fato, utilizados nas empresas.

Estudos apontam que, embora parte significativa das deficiências apontadas por Johnson e Kaplan (1987) tenha sido solucionada, ainda persiste, por parte das empresas, a utilização predominante de artefatos considerados tradicionais, tendo os artefatos modernos baixo nível de utilização, especialmente aqueles classificados no quarto estágio de evolução da International Federation of Accountants - IFAC (SOUTES; ZEN, 2005; SANTOS et al., 2014).

De forma análoga ao meio empresarial, não há constatação de os cursos de Ciências Contábeis no Brasil terem acompanhado o desenvolvimento dos negócios por meio do ensino de novos artefatos (Miranda; Riccio; Miranda, 2013), ressaltando a importância de pesquisas que avaliem o estágio de evolução dos referidos artefatos ensinados nos cursos de graduação em Ciências Contábeis.

Diante do exposto, esta pesquisa objetiva analisar as ementas pertencentes aos cursos de graduação em Ciências Contábeis, oferecidos pelas Instituições de Ensino Superior (IES) localizadas na Região Sudeste do Brasil, a fim de identificar os artefatos da Contabilidade Gerencial ensinados e os estágios de evolução nos quais os mesmos se encontram, assim como explicitar quais disciplinas contêm tais artefatos; tendo a mesma a seguinte questão de pesquisa: quais são os artefatos de Contabilidade Gerencial e o estágio de evolução em que se encontram ensinados nas IES localizadas na Região Sudeste do Brasil? Além disso, analisou-se em que disciplinas tais artefatos geralmente são apresentados aos discentes.

Com relação à relevância desta pesquisa, estudos anteriores, tais como os realizados por Marques et al. (2016), Macedo et al. (2014), Souza, Borgert e Richartz (2012) e Nascimento, Oliveira e Peter (2012) tiveram como enfoque populações e amostras distintas, visto que objetivaram analisar apenas IES públicas e/ou regiões distintas das analisadas neste trabalho, e, portanto, acredita-se que esta mesma oferece contribuição tanto para o conhecimento acadêmico como no âmbito profissional. Ademais, consoante Cunha e Borgert (2013), apenas 5\% das pesquisas acerca da área gerencial publicadas em três dos principais eventos acadêmicos contábeis no Brasil são estudos em âmbito de ensino, fato que demonstra a pertinência de estudos nesta seara.

O presente artigo apresenta, além desta introdução, a revisão de literatura, abordando Contabilidade Gerencial, artefatos de Contabilidade Gerencial e estudos anteriores. Em seguida, é apresentada a metodologia para a realização da pesquisa. Por fim, a análise de dados, as considerações finais e as referências.

\section{REFERENCIAL TEÓRICO}

O presente referencial teórico é composto por temas relevantes ao objetivo da pesquisa, quais sejam: a Contabilidade Gerencial, os artefatos de Contabilidade Gerencial, bem como pesquisas anteriores em ensino gerencial.

\subsection{A CONTABILIDADE GERENCIAL}

Para Sá (2006), o homem primitivo evidenciou, por meio de pinturas rupestres, a riqueza patrimonial que detinha, a fim de mensurá-la e gerenciá-la da melhor forma possível em momentos de escassez de recursos, tendo essa prática auxiliado no desenvolvimento da espécie humana.

$\mathrm{O}$ fato de ser necessário ter controle e gerenciar recursos igualmente é fundamental às entidades, visto que, embora no passado ter posse de informações relevantes de gestão empresarial fosse considerado um diferencial, atualmente é um requisito para a sobrevivência das empresas. Sistemas de informação contábeis bem estruturados auxiliam na tomada de decisão no que tange escolhas de cunho financeiro, auxiliando empresas a lograrem êxito em seus objetivos propostos (PAIVA, 2000).

Horngren, Sundem e Stratton (2004) definem Contabilidade Gerencial como um processo visando a identificar, mensurar, acumular, preparar, interpretar e comunicar informações que possam auxiliar gestores a atingirem seus objetivos organizacionais. Marion e Soares (2000) afirmam que muitos administradores ainda desconhecem sua utilidade, não sabendo analisar e utilizar os relatórios contábeis gerenciais existentes em suas empresas, resultando em tomadas de decisões falhas.

Anthony (1979) afirma que a Contabilidade Gerencial é voltada para usuários internos, tem ideia de futuro, não se limita às normas contábeis legais e possui subsistemas que geram informações para os gestores, suprindo suas necessidades informacionais. 
Embora considere-se a revolução industrial como um marco para a área contábil gerencial, Kaplan (1984) indica a primeira metade do século dezenove como sendo o período em que a Contabilidade Gerencial teria florescido, como resultado da demanda por informações internas que visavam o planejamento e o controle em firmas têxteis e ferroviárias, as quais necessitavam coordenar múltiplos processos de transformação de produtos.

Marco da literatura na área gerencial, a obra Relevance Lost - The Rise and Fall of Management Accounting, de Johnson e Kaplan (1987) foi responsável por trazer questionamentos com relação à adequação dos sistemas de Contabilidade Gerencial existentes na década de 1980, visto que os autores afirmavam, dentre outras coisas, que tais sistemas não estariam mais adequados ao contexto empresarial da época, bem como a percepção de haver um descompasso entre a academia e o mercado.

Em estudo posterior que analisou a obra de Johnson e Kaplan, Borinelli et al. (2005), afirmam que boa parte das deficiências citadas na obra de 1987 teria sido solucionada, embora não tenha sido possível determinar se a Contabilidade Gerencial teria recuperado sua importância, devido à falta de integração entre academia e empresas. Os autores expressam ainda que, apesar de seu valor, muitos gestores não utilizam a Contabilidade Gerencial da forma correta, fato este que pode ameaçar o futuro das empresas.

\subsection{OS ARTEFATOS DE CONTABILIDADE GERENCIAL}

Zanievicz et al. (2013) ressaltam que não há na literatura uniformidade na classificação e denominação dos ACG; contudo, para fins desta pesquisa, utiliza-se a definição de Borinelli (2006), a qual caracteriza tais artefatos como filosofias de gestão e instrumentos que atuam como condução do conhecimento teórico para a prática empresarial, funcionando como conceitos, ferramentas e instrumentos utilizados pelas organizações.

O IFAC emitiu, no ano de 1998, a publicação International Management Accounting Practice 1 (IMAP 1), cuja segunda seção, denominada Evolution and Change in Mananagement Accounting, classifica a Contabilidade Gerencial em quatro estágios evolutivos distintos, com seus focos de atuação e objetivos (GRANDE; BEUREN, 2011).

Essa evolução da Contabilidade Gerencial proposta pelo IFAC (1998) dá ensejo ao surgimento de diferentes ACG, afeitos aos objetivos de cada estágio. Autores como Soutes e Zen (2005), Nascimento, Oliveira e Peter (2012) e Souza, Borgert e Richartz (2012) ao pesquisarem sobre a utilização de artefatos gerenciais, com base no IMAP 1, propuseram a segregação de tais artefatos em tradicionais, englobando os dois primeiros estágios de evolução, e modernos, contemplando os dois últimos estágios. O quadro 1 destaca tais estágios, assim como os artefatos correspondendo a cada período e seus focos principais.

No entanto, Soutes e Zen (2005) esclarecem que não há como afirmar que determinados artefatos sejam utilizados apenas no estágio em que foram classificados, visto que, sendo fases de evolução, não há como precisar onde se encerra um estágio e se inicia outro, sendo possível apenas afirmar que ocorre a substituição de artefatos inadequados para as organizações em sua evolução.

Quadro 1 - Evolução dos Artefatos de Contabilidade Gerencial

\begin{tabular}{|c|c|c|c|}
\hline Estágios Evolutivos & Classificação & Artefatos Correspondentes & Foco Principal \\
\hline $1^{\text {a }}$ Estágio: até 1950 & Tradicionais & $\begin{array}{l}\text { Custeio por Absorção; Custeio Variável; } \\
\text { Custeio Padrão; Controle Financeiro e } \\
\text { Operacional, e Orçamento. }\end{array}$ & $\begin{array}{l}\text { Determinação dos custos e con- } \\
\text { trole financeiro. }\end{array}$ \\
\hline $2^{\circ}$ Estágio: 1950 até 1965 & Tradicionais & $\begin{array}{l}\text { Custo Padrão; Custeio ABC, Custeio RKW; } \\
\text { Orçamento de Capital; e Descentralização. }\end{array}$ & $\begin{array}{l}\text { Informação para planejamento } \\
\text { e controle gerencial. }\end{array}$ \\
\hline $3^{\circ}$ Estágio: 1965 até 1985 & Modernos & $\begin{array}{l}\text { Gestão Baseada em Atividades; Centros de } \\
\text { Responsabilidade; Preço de Transferência; } \\
\text { Custo Meta; Kaizen; Benchmarking; Just } \\
\text { in Time; GECON; Simulações; Teoria das } \\
\text { Restrições; Custeio do Ciclo de Vida. }\end{array}$ & $\begin{array}{l}\text { Redução de perdas de recursos } \\
\text { em processos organizacionais. }\end{array}$ \\
\hline $4^{\circ}$ Estágio: 1985 em diante & Modernos & $\begin{array}{l}\text { Planejamento Estratégico; Balanced Score- } \\
\text { card; Método de Avaliação de Desempen- } \\
\text { ho: (EVA), (MVA). }\end{array}$ & $\begin{array}{l}\text { Criação de valor através do uso } \\
\text { efetivo dos recursos. }\end{array}$ \\
\hline
\end{tabular}

Fonte: Adaptado de Soutes e Zen (2005)

Soutes e Zen (2005) e Santos et al. (2014) avaliaram o nível de utilização de artefatos de Contabilidade Gerencial por empresas brasileiras, bem como o estágio em que tais artefatos são classificados segundo a literatura. Concluíram que praticamente não há utilização dos artefatos considerados modernos, especialmente os que são classificados no quarto estágio.

Silva, Cecon e Marques (2016) relacionaram o estágio do ciclo de vida organizacional com o uso de ACG tradicionais e modernos em empresas do setor cíclico. Os resultados evidenciaram que as empresas em estágio de crescimento 
tendem a utilizar artefatos de Contabilidade Gerencial caracterizados pela literatura como modernos e as empresas do estágio maturidade tendem a utilizar artefatos caracterizados como tradicionais.

Os resultados obtidos por tais pesquisas demonstram que há um distanciamento entre a relevância dos estágios modernos e o que de fato está sendo utilizado nas entidades, que ressalta a importância de pesquisas que visam avaliar se o ensino contábil está de fato acompanhando o que é indicado pela literatura no que tange à temática.

\subsection{ESTUDOS ANTERIORES}

Foram encontradas pesquisas nas quais os autores avaliaram a presença de ACG, assim como seu estágio de evolução, tantos nos cursos de Ciências Contábeis como em organizações, sejam nacionais ou internacionais.

No quadro 2 são apresentados os estudos anteriores correlatos à temática pesquisada, nos quais foram analisados os estágios evolutivos dos ACG utilizados por empresas de diversos portes e origens.

Quadro 2 - Estudos anteriores sobre o estágio evolutivo dos artefatos utilizados em organizações

\begin{tabular}{|c|c|c|c|c|}
\hline Ano & Autor & Título & Objetivo da Pesquisa & Resultados \\
\hline 2005 & $\begin{array}{l}\text { Soutes e } \\
\text { Zen }\end{array}$ & $\begin{array}{l}\text { Estágios evolutivos da Contab- } \\
\text { ilidade Gerencial em empresas } \\
\text { Brasileiras. }\end{array}$ & $\begin{array}{l}\text { Identificar em qual estágio evo- } \\
\text { lutivo a Contabilidade Gerencial } \\
\text { Brasileira se encontra a partir da } \\
\text { análise de organizações. }\end{array}$ & $\begin{array}{l}\text { Os três primeiros estágios estão } \\
\text { dominados pela Contabilidade Ger- } \\
\text { encial nestas empresas e, quanto ao } \\
\text { quarto estágio, falta muito para ser } \\
\text { considerado dominado. }\end{array}$ \\
\hline 2010 & Himme & $\begin{array}{l}\text { Cost management projects in Ger- } \\
\text { many. }\end{array}$ & $\begin{array}{l}\text { Analisar os instrumentos de } \\
\text { gestão de custos utilizados por } \\
\text { empresas na Alemanha. }\end{array}$ & $\begin{array}{l}\text { A maior parte dos instrumentos de } \\
\text { gestão de custos mais utilizados são } \\
\text { considerados modernos, mais pre- } \\
\text { cisamente, do terceiro estágio. }\end{array}$ \\
\hline 2011 & $\begin{array}{l}\text { Grande e } \\
\text { Beuren }\end{array}$ & $\begin{array}{l}\text { Mudanças nas práticas de Con- } \\
\text { tabilidade Gerencial de empresas. }\end{array}$ & $\begin{array}{l}\text { Identificar mudanças nas práti- } \\
\text { cas de contabilidade Gerencial a } \\
\text { partir dos Relatórios da Adminis- } \\
\text { tração de empresas familiares. }\end{array}$ & $\begin{array}{l}\text { Os estágios } 1 \text { a } 3 \text { estão consolidados, } \\
\text { porém, o } 4 \text { não. }\end{array}$ \\
\hline 2013 & $\begin{array}{l}\text { Reis e } \\
\text { Teixeira }\end{array}$ & $\begin{array}{l}\text { Utilização de artefatos de Contab- } \\
\text { ilidade Gerencial nas sociedades } \\
\text { cooperativas agropecuárias de } \\
\text { minas gerais e sua relação com } \\
\text { porte e desempenho financeiro. }\end{array}$ & $\begin{array}{l}\text { Verificar a utilização dos artefatos } \\
\text { tradicionais e modernos de Con- } \\
\text { tabilidade Gerencial em cooper- } \\
\text { ativas agropecuárias e analisar a } \\
\text { relação com seu porte e desem- } \\
\text { penho financeiro. }\end{array}$ & $\begin{array}{l}\text { Dentre outros fatores, foi observado } \\
\text { que a maioria das cooperativas agro- } \\
\text { pecuárias analisadas utilizada artefa- } \\
\text { tos tradicionais. }\end{array}$ \\
\hline 2014 & $\begin{array}{l}\text { López e } \\
\text { Hiebl }\end{array}$ & $\begin{array}{l}\text { Management accounting in small } \\
\text { and medium-sized enterprises: cur- } \\
\text { rent knowledge and avenues for } \\
\text { further research. }\end{array}$ & $\begin{array}{l}\text { Sintetizar o conhecimento sobre } \\
\text { artefatos de Contabilidade Geren- } \\
\text { cial por parte de pequenas e médi- } \\
\text { as empresas. }\end{array}$ & $\begin{array}{l}\text { Foi encontrado, dentre outros acha- } \\
\text { dos, que a utilização dos artefatos é } \\
\text { menor por parte de pequenas e mé- } \\
\text { dias empresas quando em compara- } \\
\text { ção às organizações de maior porte. }\end{array}$ \\
\hline 2014 & $\begin{array}{l}\text { Santos } \\
\text { et al. }\end{array}$ & $\begin{array}{l}\text { Instrumentos da Contabilidade } \\
\text { Gerencial utilizados pelas micro, } \\
\text { pequenas e médias empresas: } \\
\text { estudo em uma prestadora de } \\
\text { serviços contábeis e seus respec- } \\
\text { tivos clientes. }\end{array}$ & $\begin{array}{l}\text { Verificar os instrumentos da Con- } \\
\text { tabilidade Gerencial utilizados } \\
\text { pelas micro, pequenas e médias } \\
\text { empresas de serviços contábeis. }\end{array}$ & $\begin{array}{l}\text { Praticamente não há uso dos artefa- } \\
\text { tos considerados modernos (terceiro } \\
\text { e quarto estágios), sendo os artefatos } \\
\text { do segundo estágio os mais utilizados. }\end{array}$ \\
\hline 2016 & $\begin{array}{l}\text { Silva, } \\
\text { Cecon e } \\
\text { Marques }\end{array}$ & $\begin{array}{l}\text { Relação entre os artefatos de } \\
\text { Contabilidade Gerencial e o ciclo } \\
\text { de vida organizacional de empre- } \\
\text { sas do setor de consumo cíclico. }\end{array}$ & $\begin{array}{l}\text { Relacionar o estágio de ciclo de } \\
\text { vida organizacional com o uso de } \\
\text { artefatos de Contabilidade Ger- } \\
\text { encial tradicionais e modernos, } \\
\text { em empresas do setor de con- } \\
\text { sumo cíclico. }\end{array}$ & $\begin{array}{l}\text { As empresas em estágio de cresci- } \\
\text { mento tendem a utilizar artefatos de } \\
\text { Contabilidade Gerencial caracteriza- } \\
\text { dos pela literatura como modernos } \\
\text { e as empresas do estágio maturidade } \\
\text { tendem a utilizar artefatos caracteri- } \\
\text { zados como tradicionais. }\end{array}$ \\
\hline 2018 & $\begin{array}{l}\text { Venturini e } \\
\text { Carraro }\end{array}$ & $\begin{array}{l}\text { Estágio evolutivo da Contabili- } \\
\text { dade Gerencial em organizações } \\
\text { contábeis de natureza jurídi- } \\
\text { ca eireli no município de Porto } \\
\text { Alegre-RS. }\end{array}$ & $\begin{array}{l}\text { Verificar em qual estágio da } \\
\text { Contabilidade Gerencial encon- } \\
\text { tram-se as organizações contábeis } \\
\text { de natureza jurídica EIRELI no } \\
\text { município de Porto Alegre - RS. }\end{array}$ & $\begin{array}{l}\text { As organizações analisadas se en- } \\
\text { contram no segundo estágio evoluti- } \\
\text { vo da Contabilidade Gerencial. }\end{array}$ \\
\hline
\end{tabular}

Fonte: Elaboração própria

Conforme demonstrado no quadro 2, tanto no âmbito nacional quanto no internacional, as organizações estão consolidadas no que tange a utilização de ACG classificados como pertencendo ao primeiro e segundo estágios - embora parte significativa dessas utilizem artefatos denominados modernos, com ênfase para os do terceiro estágio, como apontado nos estudos realizados por Soutes e Zen (2005), Himme (2010), Grande e Beuren (2011). 
No quadro 3 são apresentadas pesquisas nas quais os autores analisaram a utilização e, ainda, o estágio evolutivo dos ACG presentes nas ementas dos cursos de Ciências Contábeis tanto no Brasil quanto em outros países.

Quadro 3 - Estudos anteriores sobre o estágio evolutivo dos artefatos presentes nas ementas dos cursos de Ciências Contábeis

\begin{tabular}{|c|c|c|c|c|}
\hline Ano & Autor & Título & Objetivo da Pesquisa & Resultados \\
\hline 2010 & Siegel et al. & $\begin{array}{l}\text { The ongoing preparation gap } \\
\text { in management accounting } \\
\text { education: a guide for change. }\end{array}$ & $\begin{array}{l}\text { Analisar se a matriz curricular } \\
\text { em Ciências Contábeis, no que } \\
\text { tange ao âmbito gerencial, é } \\
\text { apropriada para a formação de } \\
\text { estudantes que ingressarão em } \\
\text { organizações privadas. }\end{array}$ & $\begin{array}{l}\text { Observou-se que as organizações utili- } \\
\text { zam artefatos que não estão presentes } \\
\text { em parte significativa das matrizes cur- } \\
\text { riculares. }\end{array}$ \\
\hline 2012 & $\begin{array}{l}\text { Souza, } \\
\text { Borgert e } \\
\text { Richartz }\end{array}$ & $\begin{array}{l}\text { Análise do conteúdo das } \\
\text { ementas das disciplinas rela- } \\
\text { cionadas à área gerencial. }\end{array}$ & $\begin{array}{l}\text { Identificar quais os temas contem- } \\
\text { plados nas ementas das discipli- } \\
\text { nas da área gerencial dos cursos } \\
\text { de Ciências Contábeis das Univer- } \\
\text { sidades Federais Brasileiras. }\end{array}$ & $\begin{array}{l}\text { Os temas com maior destaque nas emen- } \\
\text { tas estão: sistemas estruturados de acu- } \\
\text { mulação de custos; custos gerenciais; } \\
\text { preço de transferência e preço de venda e } \\
\text { mensuração e avaliação de desempenho. }\end{array}$ \\
\hline 2012 & $\begin{array}{l}\text { Nascimen- } \\
\text { to, Oliveira } \\
\text { e Peter }\end{array}$ & $\begin{array}{l}\text { O ensino dos artefatos de } \\
\text { Contabilidade Gerencial nos } \\
\text { cursos de graduação em } \\
\text { Ciências Contábeis }\end{array}$ & $\begin{array}{l}\text { Investigar o estágio evolutivo em } \\
\text { que se encontram os artefatos de } \\
\text { Contabilidade Gerencial presentes } \\
\text { nas ementas nos cursos de gradu- } \\
\text { ação em Ciências Contábeis. }\end{array}$ & $\begin{array}{l}\text { Os artefatos presentes nas ementas } \\
\text { analisadas encontram-se no primeiro } \\
\text { estágio evolutivo. Verificou-se ainda, } \\
\text { que as disciplinas Contabilidade de } \\
\text { Custos e Análise de Custos apresen- } \\
\text { tam-se como as maiores disseminado- } \\
\text { ras desses artefatos. }\end{array}$ \\
\hline 2013 & $\begin{array}{l}\text { Miranda, } \\
\text { Riccio e } \\
\text { Miranda }\end{array}$ & $\begin{array}{l}\text { O ensino da Contabilidade } \\
\text { Gerencial no Brasil: uma } \\
\text { avaliação de grades curricu- } \\
\text { lares e literatura didática. }\end{array}$ & $\begin{array}{l}\text { Traçar um panorama do ensino } \\
\text { de temas ligados à Contabilidade } \\
\text { Gerencial no Brasil. }\end{array}$ & $\begin{array}{l}\text { Dentre outros apontamentos, foi obser- } \\
\text { vado o baixo oferecimento de conteú- } \\
\text { dos denominados modernos. }\end{array}$ \\
\hline 2016 & $\begin{array}{c}\text { Marques } \\
\text { et al. }\end{array}$ & $\begin{array}{l}\text { Artefatos da Contabilidade Ge- } \\
\text { rencial: um estudo em cursos } \\
\text { de graduação de Ciências Con- } \\
\text { tábeis da Região Sul do Brasil. }\end{array}$ & $\begin{array}{l}\text { Identificar os artefatos de Con- } \\
\text { tabilidade Gerencial que são en- } \\
\text { sinados nos cursos de graduação } \\
\text { em Ciências Contábeis das Insti- } \\
\text { tuições de Ensino Superior (IES) } \\
\text { da Região Sul do Brasil. }\end{array}$ & $\begin{array}{l}\text { Em todos os estados analisados foram } \\
\text { observados mais frequentemente os ar- } \\
\text { tefatos do primeiro estágio. }\end{array}$ \\
\hline
\end{tabular}

Fonte: Elaboração própria

Denota-se, com base nos estudos correlatos demonstrados no quadro 3, que há maior quantidade de artefatos classificados como "tradicionais" nas matrizes curriculares dos cursos de Ciências Contábeis, com ênfase para o primeiro estágio. Depreende-se, ainda, que as temáticas relacionadas à análise dos custos gerenciais são as mais presentes nos referidos currículos.

Dessa forma, consoante estudos anteriores explicitados nos quadros 2 e 3, nota-se que há um descompasso entre os artefatos mencionados na literatura, no que tange à Contabilidade Gerencial, acerca dos estágios de evolução dos artefatos utilizados nas organizações e o que é ensinado nos cursos de contabilidade das amostras analisadas.

\section{METODOLOGIA}

Para responder ao objetivo proposto, desenvolveu-se uma pesquisa de abordagem qualitativa. Consoante Minayo, Deslandes e Gomes (2009), este tipo de pesquisa responde a questões particulares, correspondendo a um espaço mais profundo dos fenômenos, não podendo serem reduzidos à operacionalização de variáveis. Pratt (2009) afirma que a pesquisa qualitativa é melhor para responder perguntas “como" e para examinar processos de articulação

Acerca dos objetivos desta pesquisa, ela é classificada como de cunho descritivo, visto que visa expor e analisar as ementas dos cursos de graduação em Ciências Contábeis da Região Sudeste do Brasil, sendo essa a população da pesquisa. Para Vergara (2005), a pesquisa descritiva expõe características de determinada população ou de determinado fenômeno. Andrade (2002), defende que a pesquisa descritiva visa observar fatos, registrá-los, analisá-los, classificá-los e interpretá-los, sem que o pesquisador interfira neles.

Com relação aos procedimentos de coleta, este trabalho é classificado como documental, por utilizar com fonte de dados as ementas dos cursos de graduação em Ciências Contábeis. A pesquisa documental utiliza materiais que não receberam análise aprofundada, visando selecionar, tratar e interpretar a informação bruta, a fim de extrair da mesma algum sentido e dar-lhe algum valor (SILVA; GRIGOLO, 2002). 
Primeiramente, buscou-se, no site do MEC, as IES localizadas na Região Sudeste que oferecem o curso de Ciências Contábeis. Em seguida, foram desconsideradas as instituições que oferecem somente o curso na modalidade à distância, restando as que oferecem a modalidade presencial. Por fim, foram excluídos os cursos desativados, totalizando 661 instituições de ensino (MEC, 2017). Os artefatos de Contabilidade Gerencial foram categorizados em tradicionais e modernos, com base no artigo de Soutes e Zen (2005), tendo os autores utilizado como base os níveis evolutivos a partir da definição elaborada pelo IFAC (1998).

Posteriormente, buscou-se a ementa de Ciências Contábeis no portal eletrônico das IES localizadas no Sudeste do Brasil, a fim de avaliar em quais disciplinas os referidos ACG são apresentados aos discentes, a saber: Contabilidade de Custos; Análise de Custos; Contabilidade Gerencial; Controladoria; e outras disciplinas com nomenclaturas diversas e que abordam a Contabilidade Gerencial.

As disciplinas, com exceção de "Outras" e "Contabilidade Gerencial", foram selecionadas com base na Proposta Nacional de Conteúdo para os cursos de Ciências Contábeis (CFC, 2009). Ainda que essa seja apenas uma sugestão, notou-se que os principais artefatos analisados estão presentes nessas ementas.

Percebeu-se, no decorrer da elaboração desta pesquisa, que parte das IES analisadas não disponibilizam de forma eletrônica a ementa de seus cursos. Assim, a fim de aumentar a amostra a ser analisada, foram feitos contatos com as citada IES, por correio eletrônico, solicitando as ementas das disciplinas que compõem o curso de Ciências Contábeis; dessa forma, a amostra deste trabalho atingiu 53 instituições de ensino superior, conforme tabela 1.

Notou-se, ainda, que há IES que oferecem o curso de Ciências Contábeis em unidades distintas, sendo considerada, para fins desta pesquisa, apenas uma ementa, por se tratar, em geral, da mesma ementa, conforme percebido por estes autores durante a produção deste trabalho.

Tabela 1 - Passo-a-passo da construção da amostra

\begin{tabular}{|c|c|c|c|c|c|}
\hline Construção da amostra & Geral & $\begin{array}{c}\text { Espírito } \\
\text { Santo }\end{array}$ & $\begin{array}{l}\text { Minas } \\
\text { Gerais }\end{array}$ & $\begin{array}{c}\text { São } \\
\text { Paulo }\end{array}$ & $\begin{array}{l}\text { Rio de } \\
\text { Janeiro }\end{array}$ \\
\hline População da pesquisa & 826 & 68 & 208 & 402 & 148 \\
\hline $\begin{array}{l}\text { Exclusão dos cursos } \\
\text { não-presenciais }\end{array}$ & 134 & 24 & 36 & 47 & 27 \\
\hline Amostra 1 & 692 & 44 & 172 & 355 & 121 \\
\hline Exclusão dos cursos desativados & 32 & 3 & 3 & 12 & 14 \\
\hline Amostra 2 & 660 & 41 & 169 & 343 & 107 \\
\hline $\begin{array}{l}\text { Exclusão dos cursos sem ementas } \\
\text { disponibilizadas }\end{array}$ & 607 & 39 & 148 & 320 & 100 \\
\hline Amostra final & 53 & 02 & 21 & 23 & 7 \\
\hline
\end{tabular}

Fonte: Elaboração própria

Na tabela 2, a seguir, demonstra-se a composição da amostra utilizada neste estudo.

Tabela 2 - Composição da amostra utilizada

\begin{tabular}{l|c|l|c}
\hline Estado & N & Categoria Administrativa & N \\
Espírito Santo & 2 & Especial & 0 \\
Minas Gerais & 21 & Privada com fins lucrativos & 10 \\
Rio de Janeiro & 7 & Privada sem fins lucrativos & 35 \\
São Paulo & 23 & Pública Estadual & 0 \\
Organização Acadêmica & $\mathbf{N}$ & Pública Federal & 8 \\
\cline { 1 - 2 } Centro Universitário & 15 & Pública Municipal & 0 \\
Faculdade & 22 & & \\
Instituição Federal de Educação, Ciência e Tecnologia & 0 & & \\
Universidade & 16 & & $\mathbf{5 3}$ \\
Total de Instituições de Ensino Superior & & & \\
\hline
\end{tabular}

Fonte: Elaboração própria 
Com relação às IES que disponibilizam o curso de Ciências Contábeis na Região Sudeste, nota-se a predominância das localizadas no estado de São Paulo, com 23 entidades de ensino superior. No que tange à categoria administrativa das mesmas, a maioria absoluta é classificada como privada sem fins lucrativos (35), seguidas por privadas com fins lucrativos (10) e federais (08). Instituições especiais, estaduais e municipais não fazem parte da amostra.

Percebe-se a primazia de IES classificadas como faculdades (22), seguidas por universidades (16) e centros universitários (15). Não foram encontradas instituições federais de educação, ciência e tecnologia na amostra utilizada.

Ressalta-se que o interesse pelo tema da pesquisa advém das sugestões de estudos futuros nos trabalhos de Marques et al. (2016), Macedo et al. (2014), Souza, Borgert e Richartz (2012) e Nascimento, Oliveira e Peter (2012); nos quais os autores ressaltam a importância de estudos acerca desta temática com amostra ampliada e maior quantidade de artefatos, visto que esses tiveram como população IES públicas ou em regiões distintas do país, o que foi realizado neste estudo.

\section{ANÁLISE DE DADOS}

Realizou-se a análise de dados a partir das 53 ementas obtidas, tanto nos portais eletrônicos quanto por correio eletrônico, das IES que compõem a amostra. A fim de realizar o objetivo proposto para esta pesquisa, qual seja identificar e classificar em estágios de evolução os artefatos da Contabilidade Gerencial ensinados nas IES localizadas na Região Sudeste do Brasil e explicitar quais disciplinas contêm tais artefatos, elaborou-se três quadros: artefatos disponibilizados nas ementas, artefatos disponibilizados por estado e artefatos disponibilizados por disciplina.

O quadro 4 destaca os artefatos avaliados, bem como a frequência e porcentagem de participação nas ementas das IES pertencentes à amostra.

Quadro 4 - Artefatos disponibilizados nas ementas

\begin{tabular}{|c|c|c|c|c|c|c|}
\hline \multicolumn{2}{|c|}{ Classificação } & Artefato & Frequência & \multicolumn{3}{|c|}{$\%$} \\
\hline Tradicionais & $\begin{array}{l}\text { Primeiro } \\
\text { Estágio }\end{array}$ & $\begin{array}{l}\text { Custeio por absorção } \\
\text { Custeio Variável } \\
\text { Custeio Padrão } \\
\text { Controle Financeiro e Operacional } \\
\text { Orçamento } \\
\text { Média de observa } \\
\text { Custo Padrão } \\
\text { Custeio ABC RKW } \\
\text { Orçamento de Capital } \\
\text { Descentralização } \\
\quad \text { Média de observa }\end{array}$ & $\begin{array}{c}33 \\
38 \\
32 \\
0 \\
19\end{array}$ & $\begin{array}{c}62,26 \% \\
71,70 \% \\
60,38 \% \\
0,00 \% \\
35,85 \% \\
\mathbf{4 6 , 0 4} \\
60,38 \% \\
79,24 \% \\
5,66 \% \\
24,53 \% \\
7,55 \% \\
\mathbf{3 5 , 4 7}\end{array}$ & 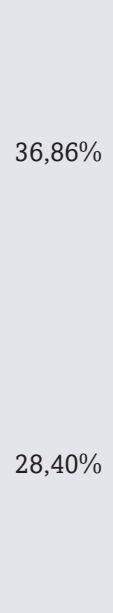 & $65,26 \%$ \\
\hline Modernos & Terceiro Estágio & $\begin{array}{l}\text { Gestão baseada em atividades } \\
\text { Centros de responsabilidade } \\
\text { Preço de transferência } \\
\text { Custo meta } \\
\text { Kaizen } \\
\text { Benchmarking } \\
\text { Just in Time } \\
\text { GECON } \\
\text { Simulações } \\
\text { Teoria das restrições } \\
\text { Custeio do ciclo de vida } \\
\quad \text { Média de observa }\end{array}$ & $\begin{array}{c}3 \\
3 \\
10 \\
3 \\
1 \\
5 \\
3 \\
10 \\
0 \\
7 \\
3\end{array}$ & $\begin{array}{c}5,66 \% \\
5,66 \% \\
18,87 \% \\
5,66 \% \\
1,87 \% \\
9,43 \% \\
5,66 \% \\
18,87 \% \\
0,00 \% \\
13,21 \% \\
5,66 \% \\
\mathbf{8 , 2 3}\end{array}$ & $14,50 \%$ & $34,74 \%$ \\
\hline
\end{tabular}




\begin{tabular}{|c|c|c|c|c|c|}
\hline Classificação & Artefato & Frequência & \multicolumn{3}{|c|}{$\%$} \\
\hline Quarto Estágio & $\begin{array}{l}\text { Planejamento estratégico } \\
\text { Balanced Scorecard } \\
\text { EVA } \\
\text { MVA } \\
\text { Média de observações }\end{array}$ & $\begin{array}{l}14 \\
26 \\
17 \\
10\end{array}$ & $\begin{array}{r}26,41 \% \\
49,06 \% \\
32,07 \% \\
18,87 \% \\
\mathbf{3 1 , 6 0}\end{array}$ & $20,24 \%$ & \\
\hline Total de observações & & 331 & & $100 \%$ & $100 \%$ \\
\hline
\end{tabular}

Fonte: Elaboração própria

Observa-se que o artefato de Contabilidade Gerencial mais disponibilizado nas ementas analisadas é o Custeio ABC (baseado em atividades), presente em 42 das 53 ementas da amostra, resultando em 79,24\%. A seguir, Custeio Variável (71,70\%), Custeio por Absorção (62,26\%) e Custeio Padrão (60,38\%). Denota-se que, embora o primeiro pertença ao segundo estágio de evolução e estes ao primeiro estágio, os três são classificados como artefatos tradicionais. Ainda, percebe-se que os artefatos: Simulações; e Controle Financeiro e Operacional não foram encontrados na amostra averiguada.

Os artefatos classificados como tradicionais constam em $65,26 \%$ das grades curriculares avaliadas, enquanto os modernos em $34,74 \%$ delas - e, dentre os estágios analisados, o que possui maior presença é o primeiro, constando em $36,86 \%$ das ementas analisadas. Portanto, conclui-se que há predominância dos artefatos tradicionais, fato que está de acordo com os resultados encontrados nas pesquisas anteriores analisadas, como as realizadas por Marques et al. (2016) e Souza, Borgert e Richartz (2012) para outras regiões estudadas.

Avaliou-se a presença de artefatos nas ementas das IES discriminadas por estados, tanto em números absolutos quanto em porcentagem, conforme explicitado no quadro 5.

Quadro 5 - Artefatos disponibilizados por estado

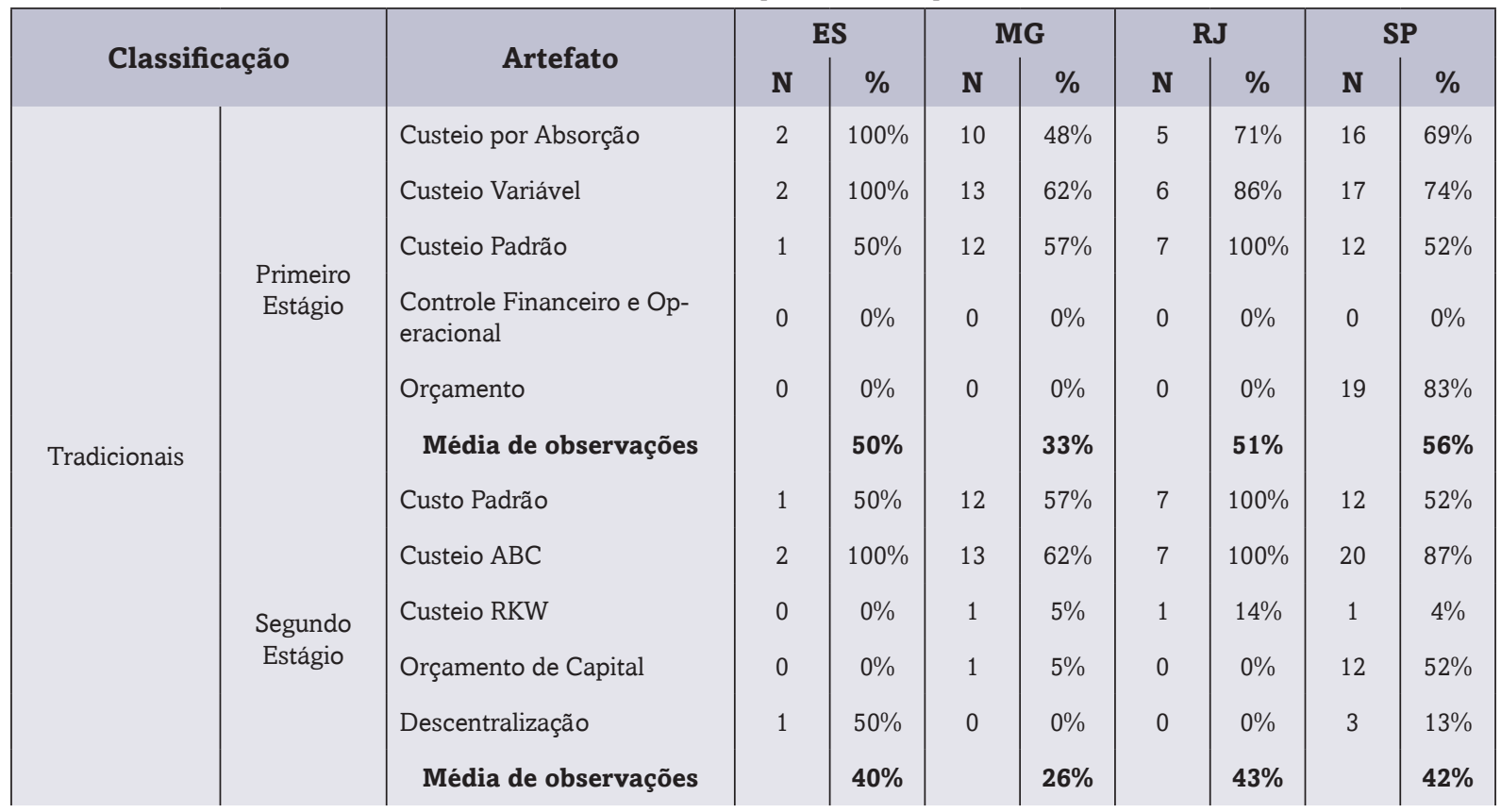




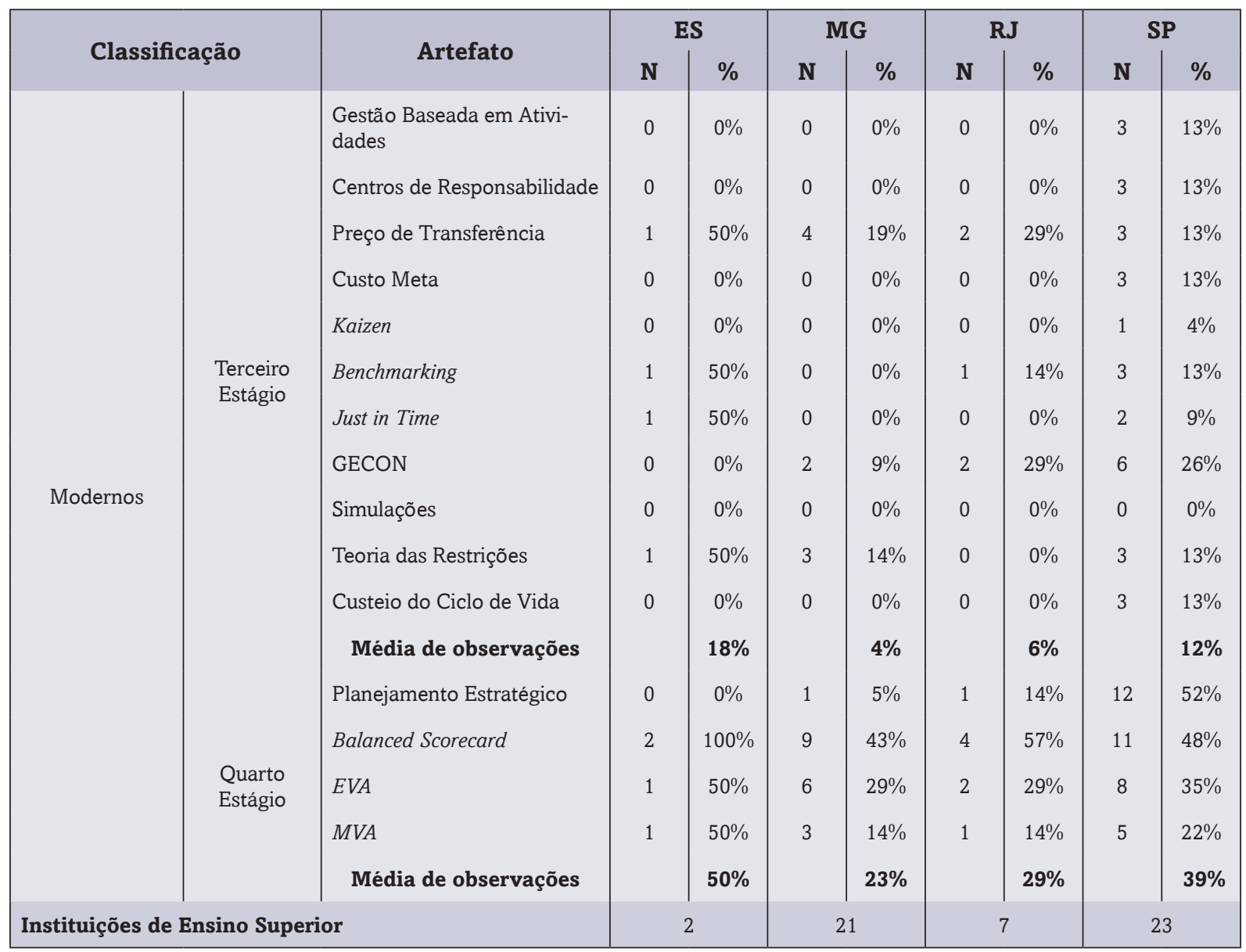

Fonte: Elaboração própria

Acerca dos estados analisados, nota-se que o estado de São Paulo possui a maior quantidade de cursos de Ciências Contábeis que incluem em suas grades artefatos tradicionais, tendo apresentado média de observação de 56\% no primeiro estágio e $42 \%$ no segundo estágio. Logo após, aparece o estado do Rio de Janeiro, com média de $51 \%$ no primeiro estágio e $43 \%$ no segundo estágio.

Com relação aos artefatos modernos, verifica-se uma baixa participação do terceiro estágio nas ementas avaliadas. Em relação aos artefatos referentes aos dois últimos estágios evolutivos, os cursos localizados no estado do Espírito Santo são os que apresentam maior frequência de artefatos, com $18 \%$, assim como a maior quantidade de artefatos do quarto estágio evolutivo, com $50 \%$.

Considerando os quatro estados da Região Sudeste, nenhum dos artefatos avaliados esteve presente em todas as ementas pertencentes à amostra desta pesquisa, o que é coerente com a distribuição de conteúdos pelas disciplinas dos cursos.

A partir dos dados obtidos, foi igualmente possível avaliar em quais disciplinas normalmente são adicionados os artefatos avaliados, conforme demonstrado no quadro 6.

Quadro 6 - Artefatos disponibilizados por disciplina

\begin{tabular}{|l|c|c|c|c|c|c|c|c|}
\hline Artefato & CC & AC & CG & CONT & OUT & $\begin{array}{c}\text { Total de } \\
\text { Ementas }\end{array}$ & $\begin{array}{c}\text { Total de } \\
\text { Instituições }\end{array}$ & S \\
Custeio por Absorção & 27 & 9 & 1 & 0 & 1 & 38 & 33 & 5 \\
Custeio Variável & 25 & 12 & 2 & 0 & 1 & 40 & 38 & 2 \\
Custeio Padrão & 10 & 17 & 3 & 0 & 2 & 32 & 32 & 0 \\
Controle Financeiro e Operacional & 0 & 0 & 0 & 0 & 0 & 0 & 0 & 0 \\
Orçamento & 1 & 0 & 0 & 3 & 15 & 19 & 32 & 32 \\
Custo Padrão & 12 & 16 & 3 & 0 & 1 & & 0
\end{tabular}




\begin{tabular}{|c|c|c|c|c|c|c|c|c|}
\hline Artefato & $\mathrm{CC}$ & AC & CG & CONT & OUT & $\begin{array}{l}\text { Total de } \\
\text { Ementas }\end{array}$ & $\begin{array}{c}\text { Total de } \\
\text { Instituições }\end{array}$ & $\mathbf{S}$ \\
\hline Custeio ABC & 26 & 15 & 2 & 1 & 2 & 46 & 42 & 4 \\
\hline Custeio RKW & 2 & 0 & 0 & 0 & 1 & 3 & 3 & 0 \\
\hline Orçamento de Capital & 0 & 0 & 1 & 1 & 11 & 13 & 13 & 0 \\
\hline Descentralização & 0 & 0 & 1 & 0 & 3 & 4 & 4 & 0 \\
\hline Gestão Baseada em Atividades & 0 & 3 & 0 & 0 & 0 & 3 & 3 & 0 \\
\hline Centros de Responsabilidade & 0 & 0 & 0 & 2 & 1 & 3 & 3 & 0 \\
\hline Preço de Transferência & 0 & 0 & 5 & 5 & 0 & 10 & 10 & 0 \\
\hline Custo Meta & 0 & 3 & 0 & 0 & 0 & 3 & 3 & 0 \\
\hline Kaizen & 0 & 0 & 0 & 0 & 1 & 1 & 1 & 0 \\
\hline Benchmarking & 0 & 0 & 0 & 2 & 3 & 5 & 5 & 0 \\
\hline Just in Time & 0 & 0 & 0 & 0 & 3 & 3 & 3 & 0 \\
\hline GECON & 0 & 0 & 0 & 9 & 1 & 10 & 10 & 0 \\
\hline Simulações & 0 & 0 & 0 & 0 & 0 & 0 & 0 & 0 \\
\hline Teoria das Restrições & 0 & 0 & 0 & 6 & 1 & 7 & 7 & 0 \\
\hline Custeio do Ciclo de Vida & 0 & 0 & 0 & 0 & 3 & 3 & 3 & 0 \\
\hline Planejamento Estratégico & 0 & 0 & 1 & 5 & 8 & 14 & 14 & 0 \\
\hline Balanced Scorecard & 1 & 0 & 2 & 22 & 2 & 27 & 26 & 1 \\
\hline EVA & 0 & 0 & 1 & 14 & 2 & 17 & 17 & 0 \\
\hline MVA & 0 & 0 & 1 & 7 & 2 & 10 & 10 & 0 \\
\hline
\end{tabular}

Legenda: CC - Contabilidade de Custos; AC - Análise de Custos; CG - Contabilidade Gerencial; CONT - Controladoria; OUT Outras; S - Sobreposição.

Fonte: Elaboração própria

A coluna "sobreposição" refere-se a artefatos que foram encontrados em mais de uma disciplina na mesma instituição de ensino superior. Tal fato ocorreu com Custeio por Absorção (5), Custeio Variável (2), Custeio ABC (4) e Balanced Scorecard (1).

A partir dos dados presentes no quadro 6, evidencia-se que na disciplina Contabilidade de Custos, os artefatos Custeio por Absorção e Custeio $\mathrm{ABC}$ foram os que mais apareceram nas ementas analisadas, com, respectivamente, 27 e 26 vezes cada; em Análise de Custos, destacaram-se Custeio Padrão e Custo Padrão, com, respectivamente, 17 e 16 aparições cada; em Contabilidade Gerencial nota-se a supremacia de Preço de Transferência, o qual está presente em cinco das ementas; e, em Controladoria, teve prevalência os artefatos Balanced Scorecard, aparecendo em 22 ementas, e EVA, em 14.

Ao observar o quadro 4, nota-se que os artefatos considerados tradicionais, principalmente os que se referem a Sistemas de Custeio, estão, em maioria, alocados nas disciplinas Contabilidade de Custos e Análise de Custos, enquanto a disciplina Controladoria é responsável pela maior parte dos artefatos modernos encontrados nas ementas analisadas.

A partir das informações contidas no presente artigo, torna-se possível concluir que o ensino de artefatos de Contabilidade Gerencial nas IES localizadas na Região Sudeste do Brasil não acompanha a literatura contábil, visto que, embora o terceiro e o quarto estágio tenham tido início, respectivamente, em 1965 e 1985, as ementas analisadas neste artigo consistem, em sua maioria, por artefatos do primeiro e segundo estágios.

Tal conclusão está de acordo com o resultado obtidos em pesquisas anteriores realizadas acerca desta temática, ainda que em populações distintas, como as de Marques et al. (2016), Macedo et al. (2014), Souza, Borgert e Richartz (2012) e Nascimento, Oliveira e Peter (2012).

O resultado do presente estudo pode servir como indício para explicar as conclusões encontradas em estudos que avaliaram a utilização de artefatos de Contabilidade Gerencial em empresas brasileiras e estrangeiras, como os explicitados no quadro 2, ou seja, a baixa presença de artefatos modernos no ensino dos cursos de Ciências Contábeis pode influenciar negativamente a percepção dos discentes com relação ao seu uso, além de aumentar o distanciamento entre a academia e a prática.

\section{CONSIDERAÇÕES FINAIS}

Nesta pesquisa, de cunho descritivo, com abordagem qualitativa e análise documental, foram analisadas as ementas de 53 IES dos quatro estados que compõem a Região Sudeste do Brasil, totalizando 331 observações. O objetivo desta foi 
identificar os artefatos de Contabilidade Gerencial ministrados aos discentes do curso de Ciência Contábeis, assim como o estágio de evolução ao qual pertencem e a disciplina em que são alocados.

Quanto aos resultados, observou-se que há maior predominância do ensino dos artefatos tradicionais da Contabilidade Gerencial - quais sejam artefatos do primeiro e segundo estágios evolutivos -, com ênfase para o primeiro estágio. Os artefatos que apresentaram maior frequência foram o Custeio ABC, Custeio Variável, Custeio por Absorção e Custeio Padrão/Custo Padrão; ao passo que os que tiveram menor frequência foram Controle Financeiro e Operacional, Simulações, Kaizen e Custeio do Ciclo de Vida.

Ao analisar os dados por estado, pôde-se perceber que o estado de São Paulo apresentou maior incidência do ensino de ACG, entre os quatro estados da Região Sudeste do país. Dentre as cinco IES que mais ensinam artefatos, as quatro primeiras são de São Paulo e a quinta é do estado do Espírito Santo.

Quanto ao ensino dos artefatos modernos, os estados de São Paulo e Espírito Santo se destacam; entretanto, deve-se considerar que a amostra do Espírito Santo é composta por somente duas IES, enquanto a de São Paulo por vinte e três. Considerando-se este fato, as IES de São Paulo apresentam maior incidência de artefatos presentes nas ementas em todos os estágios, fato este que está em consonância com os resultados obtidos na pesquisa realizada por Macedo et al. (2014), tendo esses autores identificado a Universidade de São Paulo (USP) como a instituição que aborda a maior quantidade de tópicos relacionados à área gerencial no país.

Com relação às disciplinas relacionadas a artefatos de Contabilidade Gerencial, observou-se que Métodos e Sistemas de Custeio foram mais observados na disciplina de Contabilidade de Custos, enquanto Filosofias e Modelos de Gestão foram mais frequentes na disciplina de Controladoria, semelhante ao que foi encontrado por Marques et al. (2016) em seu estudo.

Constatou-se, também, que nas disciplinas “Contabilidade de Custos" e "Análise de Custos" há maior predominância de artefatos tradicionais, em detrimento dos artefatos modernos. Assim como encontrado por Nascimento, Oliveira e Peter (2012), essas também são as disciplinas cujas ementas contêm maior quantidade de artefatos de Contabilidade Gerencial. O oposto foi observado na disciplina denominada Controladoria, visto que essa se destaca por abranger com maior frequência os artefatos modernos, fato que também corresponde ao resultado encontrado por aqueles autores.

Com base nos resultados encontrados nesta pesquisa e na literatura pertinente, como as pesquisas realizadas por Soutes e Zen (2005), Grande e Beuren (2011), Santos et al. (2014), e outras explicitadas no quadro 2 do presente estudo, verifica-se que há um descompasso no que tange ao ensino e ao uso de artefatos de Contabilidade Gerencial, isto é, entre o que é ensinado aos discentes de Ciências Contábeis no Brasil e o que de fato é utilizado pelas empresas. As pesquisas demonstram que, no geral, os três primeiros estágios estão dominados pelo mercado laboral, ao passo que as IES possuem ementas que focam nos dois primeiros estágios, tendo maior ênfase no primeiro estágio. Tal desarmonia pode comprometer a qualidade das tomadas de decisões nas organizações, levando a inefetividade econômica em larga escala.

Acerca das limitações deste trabalho, cabe mencionar a utilização de uma amostra intencional e não-probabilística, bem como o baixo quantitativo de ementas disponibilizadas pelas instituições de ensino, seja em seus websites ou após contato via correio eletrônico. Outra questão a se destacar é a impossibilidade de se garantir que os docentes das IES analisadas de fato ministram no ambiente de sala de aula os artefatos que constam das ementas dispostas.

Como sugestão para futuras pesquisas, sugere-se a aplicação do tema analisado nesta pesquisa em outras regiões do país, visto que, considerando-se trabalhos que consideraram tanto IES particulares quanto públicas, esses foram realizados apenas nas regiões Sudeste e Sul do Brasil.

\section{REFERÊNCIAS}

ANDRADE, M. M. Como preparar trabalhos para cursos de pós-graduação: noções práticas. 5. ed. São Paulo: Atlas, 2002.

ANTHONY, R. Accounting, text and cases. Homewood: Irwin, 1979

BORINELLI, M. L. Estrutura conceitual básica de controladoria: sistematização à luz da teoria e das práxis. São Paulo, 2006. Tese (Doutorado em Ciências Contábeis) - Programa de Pós-Graduação em Ciências Contábeis, Departamento de Contabilidade e Atuária, Faculdade de Economia, Administração e Contabilidade da Universidade de São Paulo. São Paulo, 2006. Disponível em: <http:// www.teses.usp.br/teses/disponiveis/12/12136/tde-19032007-151637/en.php>. Acesso em: 20 jul. 2017.

BORINELLI, M. L. et al. Relevance lost: uma releitura. In Anais do IX Congresso Internacional de Custos (pp. 1-16). São Paulo: USP. Anais... São Paulo, 2005. Disponível em: <http://anaiscbc.emnuvens.com.br/anais/article/view/2131>. Acesso em: 15 ago. 2017.

BRASIL. Ministério da Educação. Instituições de Ensino Superior e Cursos Cadastrados. Brasília, DF, 2017. Disponível em: $<$ http://emec.mec.gov.br>. Acesso em 10 ago. 2017.

CONSELHO FEDERAL DE CONTABILIDADE - CFC. Proposta nacional de conteúdo para o curso de graduação em Ciências Contábeis. Brasília, 2009. Disponível em: <http://portalcfc.org.br/wordpress/wp-content/uploads/2013/01/proposta.pdf>. Acesso em: 02 set. 2017.

CUNHA, L. C; Borgert, A. Os Conteúdos de Custos nos Cursos de Graduação em Ciências Contábeis do Brasil. In: ENCONTRO ANUAL DA ANPAD, 2013, Rio de Janeiro. Anais... Rio de Janeiro: Associação Nacional de Pós-Graduação em Administração - ANPAD, 2013.

GRANDE, J. F.; BEUREN, I. M. Mudanças nas práticas de Contabilidade Gerencial de empresas. Revista de Administração Faces Journal, v. 10, n. 3, p. 84-104, 2011. Disponível em: <http://www.fumec.br/revistas/facesp/article/view/636>. Acesso em: 22 jul. 2017. 
HIMME, A. Cost management projects in Germany. Cost Management, v. 24, p. 24-33, 2010. Disponível em: <https://repository.vlerick.com/handle/20.500.12127/4983>. Acesso em: 20 mai. 2019.

HORNGREN, C. T.; SUNDEM, G.; STRATTON, W. O. Contabilidade gerencial. Prentice Hall: São Paulo, 2004.

INTERNATIONAL FEDERATION OF ACCOUNTANTS (IFAC). International management accounting practice statement: Management accounting concepts. Nova Iorque, 1998.

JOHNSON, T.; KAPLAN, R. S. Relevance lost - the rise and fall of management accounting. Boston: Harvard Business School Press, 1987.

KAPLAN, R. S. The evolution of management accounting. Readings in Accounting for Management Control, n.1, p.586-621, 1984.

LAVIA LÓPEZ, Oro; HIEBL, Martin R. W. Management accounting in small and medium-sized enterprises: current knowledge and avenues for further research. Journal of Management Accounting Research, v. 27, n. 1, p. 81-119, 2014. Disponível em: <http://www.aaajournals.org/doi/abs/10.2308/jmar-50915>. Acesso em: 22 mai. 2019.

MACEDO, L. C. B. et al. Avaliação dos conteúdos das disciplinas relacionadas à área gerencial: um estudo em universidades públicas estaduais no brasil. Registro Contábil, v. 6, n. 1, p. 52-70, 2014. Disponível em: < http://www.seer.ufal.br/index.php/registrocontabil/article/view/1311>. Acesso em: 28 ago. 2017.

MARION, J. C.; SOARES, A, H. Contabilidade como instrumento para tomada de decisões. Campinas: Alínea, 2000.

MARQUES, L. et al. Artefatos de Contabilidade Gerencial: um estudo em cursos de graduação de Ciências Contábeis da Região sul do Brasil. Revista Contexto. V. 16, n. 34, 2016. Disponível em: <http://www.seer.ufrgs.br/ConTexto/article/viewFile/66770/ pdf>. Acesso em: 11 ago. 2017.

MINAYO, M. C. S.; DESLANDES, S. F.; GOMES, R. Pesquisa social: teoria, método e criatividade. 28.ed. Rio de Janeiro Vozes, 2009.

MIRANDA, C. S.; RICCIO, E. L.; MIRANDA, R. A. M. O ensino da Contabilidade Gerencial no Brasil: uma avaliação de grades curriculares e literatura didática. Revista Contabilidade e Controladoria, v. 5, n. 2, p. 25-42, 2013. Disponível em: <https://revistas. ufpr.br/rcc/article/view/29980>. Acesso em: 15 set. 2017.

NASCIMENTO, C. P. S.; OLIVEIRA, T. E.; PETER, M. G. A. O Ensino dos Artefatos de Contabilidade Gerencial nos Cursos de Graduação em Ciências Contábeis. In: CONGRESO DE COSTOS DEL MERCOSUR, 6., Anais... Punta Del Leste, 2012. Disponível em: <http://website.acep.org.br/2011/wp-content/uploads/2014/11/ARTIGO-91.pdf>. Acesso em: 25 ago. 2017.

PAIVA, S. B. O processo decisório e a informação contábil: entre objetividades e subjetividades. Revista Brasileira de Contabilidade, Brasília, n. 123, p. 76-83, 2000.

PRATT, M. From the editors: for the lack of a boilerplate - tips on writing up (and reviewing) qualitative research. The Academy of Management Journal, v. 52, n. 5, p. 856-862, 2009.

SÁ, A. L. Teoria da Contabilidade. 4. Ed. São Paulo: Atlas, 2006.

REIS, A.; TEIXEIRA, A. Utilização de artefatos de Contabilidade Gerencial nas sociedades cooperativas agropecuárias de minas gerais e sua relação com porte e desempenho financeiro. Revista de Educação e Pesquisa em Contabilidade, v. 7, n. 4, 28 out. 2013. Disponível em: <http://www.repec.org.br/repec/article/view/997>. Acesso em: 18 mai. 2019.

SANTOS, V. et al. Instrumentos da Contabilidade Gerencial utilizados pelas micro, pequenas e médias empresas: estudo em uma prestadora de serviços contábeis e seus respectivos clientes. In: Anais... XXI Congresso Brasileiro de Custos, 2014. Disponível em: <https://anaiscbc.emnuvens.com.br/anais/article/view/3702>. Acesso em: 28 ago. 2017.

SIEGEL, Gary. et al. The ongoing preparation gap in management accounting education: a guide for change. Management Accounting Quarterly, v. 11, n. 4, p. 29, 2010.

SILVA, M. Z.; CECON, B.; MARQUES, L. Relação Entre os Artefatos de Contabilidade Gerencial e o Ciclo de Vida Organizacional de Empresas do Setor de Consumo Cíclico. In: CONGRESSO USP DE CONTABILIDADE. 16, 2016, São Paulo. Anais... São Paulo, 2016. Disponivel em: <https://congressousp.fipecafi.org/anais/artigos162016/175.pdf>. Acesso em: 25 ago. 2017.

SILVA, M; GRIGOLO, T. M. Metodologia para iniciação científica à prática de pesquisa e da extensão II. Caderno Pedagógico. Florianópolis: Udesc, 2002.

SOUZA, F. R.; BORGERT, A.; RITCHARZ, F. Análise do Conteúdo das Ementas das Disciplinas Relacionadas à Área Gerencial. In: ENCONTRO ANUAL DA ANPAD, v. 10, n. 20, 2012, Rio de Janeiro. Anais... Rio de Janeiro: Associação Nacional de Pós-Graduação em Administração - ANPAD, 2012.

SOUTES, D. O.; ZEN, M. J. Estágios evolutivos da Contabilidade Gerencial em empresas brasileiras. In: CONGRESSO USP DE CONTABILIDADE. 5, 2005, São Paulo. Anais... São Paulo, 2005.

VENTURINI, Lauren Dal Bem; CARRARO, Wendy Beatriz Witt Haddad. Estágio evolutivo da Contabilidade Gerencial em organizações contábeis de natureza jurídica eireli no município de Porto Alegre-RS. In: Anais... XXV Congresso Brasileiro de Custos, 2018. Disponível em: <https://anaiscbc.emnuvens.com.br/anais/article/view/4532>. Acesso em: 24 mai. 2019.

VERGARA, S. C. Projetos e relatórios de pesquisa em administração. São Paulo: Atlas, 2005.

ZANIEVICZ, M. et al. Métodos de custeio: uma meta-análise dos artigos apresentados no Congresso Brasileiro de Custos no período de 1994 a 2010. Revista Brasileira de Gestão de Negócios. São Paulo, v. 15, n. 49, p. 601-616, out./dez.2013. Disponível em: <http://www.scielo.br/pdf/rbgn/v15n49/1983-0807-rbgn-15-49-601.pdf>. Acesso em 02 set. 2017. 